\title{
MODELOS DETERMINÍSTICOS DE GESTÃO DE ATIVO/ PASSIVO: UMA APLICAÇÃO NO BRASIL
}

\section{Nicolas Saad}

Gestor de Fundos da HSBC Asset Management

E-mail: nicolas.s.saad@hsbc.com.br

\section{Celma O. Ribeiro}

Profa. Dra. do Depto. de Eng a ${ }^{\text {a }}$ de Produção da Escola Politécnica da USP

E-mail:celma@usp.br

\section{RESUMO}

Este artigo apresenta uma aplicação de modelos de otimização do tipo Gestão Ativo/Passivo (Asset) Liability Management ou ALM ${ }^{1}$ no Brasil. Esses modelos, ao contrário dos modelos tradicionais de maximização de ganhos sujeitos a limitações de risco, buscam otimizar a aplicação de recursos de uma entidade, dadas as características de seus passivos. A idéia central do trabalho é aplicar e adaptar alguns dos modelos existentes de otimização de carteiras do tipo Asset/Liability Management, apresentados na literatura, à realidade brasileira. A aplicabilidade dos modelos será analisada com base em um plano de aposentadoria complementar pertencente a um Fundo Multipatrocinado.

Palavras-chave: Gestão Ativo/Passivo, Carteiras de Ativos, Finanças.

\section{ABSTRACT}

This paper presents an application of Asset Liability Management (ALM) optimization models in Brazil. As opposed to traditional profit maximization models, which are subject to risk limitations, these models seek to optimize the riskreward relation. This paper aims to apply and adapt some existing asset/liability portfolio optimization models, presented in literature, to the Brazilian reality. Some concepts about Brazilian pension funds are discussed and the applicability of the models is analyzed on the basis of data from a Brazilian pension fund.

Keywords: Asset Liability Management, Portfolio, Finance. 


\section{INTRODUÇÃO}

Questões referentes a reformas da Previdência Pública no Brasil têm levado a uma maior preocupação das empresas com a questão de aposentadoria complementar. No Brasil, a Previdência Pública representou, por um longo período de tempo, a principal entidade que prestava esse tipo de serviço. $O$ instituto de Previdência Pública no Brasil trabalha em regime de repartição, e, durante o período de elevadas taxas de inflação, nem fazia sentido a discussão de migração para um regime de capitalização, pois havia um elevado risco de que a rentabilidade dos ativos fosse corroída pela inflação.

Com a redução das taxas de inflação ocorrida na década de 90 , começou a ganhar força a preocupação com o desenvolvimento de um sistema de previdência baseado na capitalização. A partir dessa década, embora já estivessem regulamentadas desde meados da década de 70, as instituições de Previdência Privada tiveram um desenvolvimento mais acentuado, uma vez que, com a estabilidade econômica, muitas empresas se sentiram estimuladas a oferecer a seus funcionários o benefício de Previdência Complementar.

A gestão de recursos de entidades de previdência complementar (principalmente ligadas a empresas privadas), muitas vezes, é realizada por empresas administradoras de recursos de terceiros, que, em alguns casos, são também responsáveis pela gestão de fluxos de caixa dessas entidades (administração do passivo). A gestão de fluxos de caixa é um importante problema em finanças de per se, e adquire especial destaque nesse contexto, em que se deve assegurar pagamentos futuros num horizonte temporal longo.

Por sua vez, um ramo de pesquisa bastante desenvolvido na área de finanças é a gestão de ativo/ passivo (Asset/Liability Management). O Asset/ Liability Management (ALM) é uma forma de gestão de recursos que considera, para tomar as decisões de investimentos, os fluxos de caixa projetados para o passivo. Esses modelos ainda são pouco empregados no Brasil, o que cria uma oportunidade para que se desenvolvam produtos novos e sofisticados nessa área.

Alguns fatores têm contribuído para um crescente interesse dos Fundos de Pensão nas metodologias de Asset/Liability Management. O primeiro deles vem a ser a estabilização da economia promovida pelo Plano Real, que permitiu que as projeções atuariais ganhassem confiabilidade. Além disso, a regulamentação sobre fundos de pensão (Resolução n-2829 do Conselho Monetário Nacional) alerta para a importância de se administrarem os ativos tendo em vista as necessidades do passivo, criando, ainda, a responsabilidade legal dos gestores de Fundos de Pensão por eventuais desequilíbrios. Além disso, as dificuldades recentes de se superarem as metas atuariais ${ }^{2}$, que não consideram as especificidades do passivo de cada plano, têm sido um incentivo à busca de novas metodologias para a definição do processo de investimentos para fundos de pensão.

A adoção de políticas previdenciárias e a preocupação em assegurar benefícios à população de idade mais avançada têm se tornado prioritárias em inúmeros países. Como conseqüência, um crescente número de trabalhos científicos tem investigado modelos apropriados à gestão de ativo/passivo. Dentro da extensa literatura sobre modelos matemáticos para a gestão de fundos de pensão, há poucos adaptáveis à realidade brasileira. Pretende-se, neste trabalho, apresentar alguns modelos ALM determinísticos e estudar sua implementação em um plano de pensão brasileiro.

\section{CONCEITOS SOBRE PREVIDÊNCIA PRIVADA NO BRASIL}

Entidades de previdência são instituições que possuem como atividade principal a captação de recursos para o pagamento de aposentadorias dos indivíduos participantes do sistema. Há dois regimes em que as entidades de previdência podem trabalhar, o regime de repartição (também chamado de pay as you go) e o regime de capitalização. No primeiro caso,

\footnotetext{
${ }^{2}$ As metodologias de meta atuarial consistem em se estabelecer uma rentabilidade real mínima dos ativos que mantenha o superávit econômico (ativos menos valor presente dos passivos) estável. Normalmente, usam-se metas atuariais como IGP-M/INPC + 5\%/6\% a.a. As baixas taxas de juros reais observadas após a desvalorização cambia de 1999 impediram o cumprimento da meta atuarial por muitas fundações nos anos que se seguiram.
} 
a instituição capta recursos dos participantes ativos, pagando benefícios aos participantes já aposentados (como no INSS). Nessas condições, podem surgir déficits, que deverão ser financiados pela entidade que patrocina o plano de previdência. No regime de capitalização, a instituição de previdência capta os recursos e forma uma poupança, que é administrada de forma a garantir o pagamento dos benefícios quando da aposentadoria dos participantes.

Sob a ótica das empresas administradoras de recursos de terceiros, há duas classes de clientes: uma delas são as Fundações propriamente ditas, ou seja, organizações com a finalidade de administrar os fundos de pensão das empresas patrocinadoras. Além delas, há as Patrocinadoras que, para não arcarem com os custos de manter uma Fundação, aderem a um Fundo de Pensão Multipatrocinado administrado por essas empresas.

Tanto as Fundações quanto o Fundo de Pensão Multipatrocinado (FPM) visam a garantir aos funcionários das empresas patrocinadoras planos de aposentadoria complementar, que se traduzem em uma renda extra que começa a ser paga a partir da data de aposentadoria do beneficiário. A fim de garantir o pagamento dos benefícios, os planos de previdência recebem contribuições das empresas patrocinadoras e/ou dos participantes (funcionários das patrocinadoras, que receberão a aposentadoria complementar). Esses recursos (ativo) são aplicados ao longo do tempo, de forma a cobrir os benefícios futuros. A obrigação já estabelecida desses planos de previdência, associada à expectativa de benefícios a serem pagos no futuro, caracteriza o passivo dos mesmos.

Quanto à forma de patrocínio, podem-se distinguir três tipos básicos de planos de Previdência Complementar no Brasil: fechados, multipatrocinados e abertos.

Os planos fechados são aqueles nos quais uma empresa (a patrocinadora) cria uma instituição independente (uma Fundação) responsável pela gestão das contribuições e do pagamento do benefício aos participantes. Assim, o participante e a Patrocinadora contribuem mensalmente com uma parcela do salário do funcionário, e a Fundação pode fazer a gestão dos ativos e dos passivos, podendo terceirizar parcial ou totalmente essas atividades. Nesse caso, o vínculo do participante com o plano está atrelado ao seu vínculo com a empresa, sendo que, em situações de desligamento, deve ser dado um tratamento específico.

Os Fundos de Pensão Multipatrocinados são planos de aposentadoria complementar nos quais há mais de uma empresa patrocinadora. Nessa situação, as empresas evitam os custos de manutenção de uma Fundação independente, aproveitando-se do ganho de escala propiciado. Em outras palavras, ao optar pela adesão a um Fundo Multipatrocinado, a Patrocinadora divide com todos os outros patrocinadores os custos fixos associados à gestão do plano, como despesas administrativas, despesas com instalações, etc. Normalmente, assim como nos planos fechados, o vínculo do participante com o Fundo Multipatrocinado está atrelado ao seu vínculo com a empresa.

Por fim, existem os Planos Abertos, que são fundos voltados para a adesão individual, e que independem do vínculo com a empresa. Nessa situação, as contribuições são, em geral, feitas integralmente pelo participante, que tem liberdade maior na administração de sua poupança. Uma classe de produtos que tem apresentado taxas de crescimento significativas nessa área, por seus benefícios fiscais, é a dos PGBLs (Planos Geradores de Benefícios Livres).

É possível, ainda, dividir os planos de previdência complementar em dois grandes grupos de características bastante distintas: os planos do tipo Benefício Definido (BD) e os planos do tipo Contribuição Definida (CD).

Nos planos CD, o participante e a empresa contribuem com uma parcela mensal, e o benefício recebido após a aposentadoria depende exclusivamente da massa de recursos acumulada ao longo do período, bem como dos rendimentos associados à administração desses recursos. Nesse caso, no ato da aposentadoria, calcula-se, a partir do saldo do participante e de sua expectativa de vida, o valor do benefício que ele receberá ${ }^{\text {. }}$ Assim, não há risco para a patrocinadora, pois não existe compromisso de proporcionar uma renda predeterminada ao participante após a aposentadoria.

Nesse tipo de plano, a metodologia ideal de administração do ativo seria a segmentação de perfis,

\footnotetext{
${ }^{3}$ Normalmente, o participante pode optar por receber o saldo que possui no fundo em um determinado número de parcelas, podendo, inclusive, resgatá-lo integralmente e estabelecer, com uma seguradora, um contrato de renda vitalícia.
} 
que permitiria ao participante selecionar um portfolio com características que atendessem a seus objetivos de rentabilidade e que fossem compatíveis com sua tolerância ao risco. Dessa forma, um participante que estivesse próximo da aposentadoria apresentaria uma aversão ao risco significativamente superior a um outro no início de sua carreira.

A outra modalidade de planos de previdência complementar existente é a dos planos Benefício Definido, nos quais o complemento de aposentadoria a ser recebido pelo participante é função de seu salário ao longo do período de contribuição. Dessa forma, o passivo, ou seja, o compromisso indiretamente assumido pela patrocinadora, é independente das oscilações do ativo. O principal risco para esse tipo de plano é o de que haja uma falta de recursos para financiar os benefícios futuros, ou seja, um déficit, que deverá ser financiado pela patrocinadora.

Os planos CD podem ser considerados, portanto, menos arriscados para a patrocinadora, sob o ponto de vista de que ofertam um benefício extra para seus funcionários sem o risco da necessidade futura de injeção de recursos no plano. A migração de planos $\mathrm{BD}$ para $\mathrm{CD}$ tem sido um processo forte na indústria de previdência complementar brasileira, e hoje a estrutura BD responde por uma parcela muito menor do que há alguns anos, quando era dominante.

Para a administração dos planos $\mathrm{BD}$, os métodos de Asset/Liability Management apresentam boa aderência às necessidades da Patrocinadora, que possui o objetivo primordial de evitar o surgimento de déficits futuros. Assim, as metodologias a serem estudadas se aplicam principalmente à gestão dos recursos dos planos de previdência do tipo benefício definido, e os dados coletados para a realização do estudo referemse a um plano que opera nesse regime.

\section{MODELOS DE ASSET/LIABILITY MANAGEMENT}

Serão apresentados modelos de Asset/Liability Management adequados a planos Benefício Definido. Para esse tipo de plano, a gestão dos ativos deve ser voltada para o completo financiamento do passivo que surgirá como decorrência das aposentadorias dos participantes. Nesse caso, não é necessário que haja a segmentação, pois o benefício recebido pelo participante independe da rentabilidade obtida.

\section{Modelos de Imunização}

Um modelo usualmente utilizado para se fazer a administração conjunta de ativos e passivos é o de duration matching. A idéia central é maximizar a rentabilidade dos ativos da carteira sujeito às restrições de Patrimônio (Valor Presente dos ativos igual ao Valor Presente do passivo) e de duration. É sabido que, quando há um aumento nas taxas de juros, por exemplo, os valores presentes dos fluxos de caixa caem. Porém, em função da configuração dos fluxos de caixa, os ativos apresentarão diferentes sensibilidades em relação às variações nas taxas de juros. A medida dessa sensibilidade é denominada de dollar duration do ativo e consiste na derivada do seu valor presente em relação à taxa de juros. Para eliminar a unidade monetária, uma forma mais utilizada de determinação da sensibilidade à taxa de juros é o quociente entre o dollar duration e o valor presente, que é conhecida simplesmente como duration e é medida em períodos.

Sendo assim, a forma de se equiparar a sensibilidade dos valores presentes de ativos e passivos em relação à taxa de juros é igualarem-se os dollar durations de ambos, obrigando a composição do portfolio a ser tal que, se houver aumento da taxa de juros, os valores do ativo e do passivo cairão na mesma proporção e, se houver redução da taxa, haverá aumento dos Valores Presentes de ativos e passivos na mesma magnitude. O dollar duration é definido como:

$$
k=-\sum_{r}\left(t \times \frac{F C x_{i}}{(1+i)^{(t+1)}}\right)
$$

onde os valores $\left(F C x_{t}\right)$ são os fluxos de caixa de cada período. A partir daí, obtém-se a seguinte forma matemática do modelo [IMMUNIZATION1]:

\section{Modelo [IMMUNIZATION1]:}

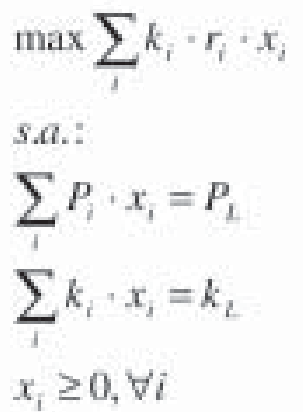


Aqui:

$P i$ é o valor presente do ativo $i$;

$P_{L}$ é o valor presente do passivo;

$r_{i}$ é a taxa interna de retorno do ativo $i$;

$k_{i}$ é o dollar duration do ativo $i$;

$\mathrm{k}_{\mathrm{L}}$ é o dollar duration do passivo;

$\mathrm{x}_{\mathrm{i}}$ é a quantidade do ativo $i$, ou seja, o valor financeiro a ser investido no ativo $i$ dividido pelo seu valor presente.

O modelo [IMMUNIZATION1], portanto, busca montar uma carteira de máxima rentabilidade que possua a mesma sensibilidade às taxas de juros que o passivo.

Observe que as taxas de juros não precisam ser necessariamente constantes ao longo do tempo, podendo ser extraídas a partir da curva de juros de mercado. Nesse caso, o dollar duration ainda pode ser utilizado se supusermos que as variações das taxas de juros serão iguais independentemente do prazo, ou, em outras palavras, que as derivadas parciais do valor presente em relação à taxa de cada prazo serão iguais. Outra observação interessante que se pode fazer aqui a respeito dos modelos de Asset/ Liability Management, de uma forma geral, é a de que, contrariamente à utilização de uma taxa de desconto arbitrária para o passivo (por exemplo taxa real de $6 \%$ a.a.), tais modelos utilizam as taxas de juros de mercado para chegar ao valor presente das obrigações do plano, o que é conceitualmente mais adequado. Como as taxas de juros de mercado são superiores às taxas atuariais, o status financeiro real dos planos, interpretado por modelos de ALM, é melhor que o status indicado pelo superávit calculado como ativos menos reservas matemáticas.

Obrigar que ativos e passivos tenham uma mesma variabilidade em relação à taxa de juros pode não ser suficiente para garantir que o valor presente do passivo não supere o valor presente do ativo, pois o passivo pode, na margem, aumentar seu valor mais que o ativo, gerando déficit (ou seja, o dollar duration do passivo poderia ter um comportamento desfavorável, aumentando mais rápido que o dollar duration do ativo conforme as taxas de juros caem ou se reduzindo mais rápido quando as taxas de juros sobem).

Para solucionar esse problema, pode-se impor que a segunda derivada do valor presente do ativo em relação à taxa de juros seja maior que a segunda derivada do valor do passivo em relação a tal taxa.
Essa segunda derivada do valor presente em relação à taxa é denominada dollar convexity, ou convexidade, e é calculada da forma indicada abaixo:

$$
Q=\sum_{t}\left(t \times(t+1) \frac{F C x_{t}}{(1+i)^{(j-2)}}\right)
$$

Ou seja, se se puder obrigar a carteira da solução a possuir uma convexidade maior ou igual à do passivo, terse-á um portfolio que tenderá, quando houver variações na taxa de juros, a ganhar mais valor (ou perder menos valor) que o passivo. Esse modelo [IMMUNIZATION2] pode ser escrito matematicamente como segue:

Modelo [IMMUNIZATION2]:

$$
\begin{aligned}
& \max \sum_{i} k_{i} \cdot r_{i} \cdot x_{i} \\
& \text { s.a.: } \\
& \sum_{i} P_{i} \cdot x_{i}=P_{L} \\
& \sum_{i} k_{i} \cdot x_{i}=k_{L} \\
& \sum_{i} Q_{i} \cdot x_{i} \geq Q_{L} \\
& x_{i} \geq 0, \forall i
\end{aligned}
$$

Onde:

$P i$ é o valor presente do ativo $i$;

$P_{L}$ é o valor presente do passivo;

$r_{i}$ é a taxa interna de retorno do ativo $i$;

$k_{i}$ é o dollar duration do ativo $i$

$\mathrm{k}_{\mathrm{L}}$ é o dollar duration do passivo;

Qi é o dollar convexity do ativo $i$;

Qu é o dollar convexity do passivo;

$\mathrm{x}_{\mathrm{i}}$ é a quantidade do ativo $i$, ou seja, o valor a ser investido no ativo $i$ dividido pelo seu valor presente.

Quando se impõe a restrição de duration analisada acima, supõe-se que, caso haja uma variação nas taxas de juros, conforme foi mencionado, ela será igual para todos os prazos. Dessa forma, a carteira gerada estará imunizada em relação a mudanças paralelas na curva de juros porém, se houver um deslocamento com alteração na forma da curva, os valores de ativos e passivos poderão não variar de forma homogênea.

Uma forma interessante de se minimizar esse risco de formato da curva (shape risk) é a de se dividir o passivo em diversos subgrupos com vencimentos concentrados em datas diferentes e de se realizar a 
otimização [IMMUNIZATION1] ou [IMMUNIZATION2] para cada subgrupo separadamente. Há outros modelos de imunização (Fabozzi (2000)) que têm como função objetivo a ser minimizada o próprio risco do modelo (immunization risk) e podem ser aplicados com o mesmo fim.

\section{Modelos de Cash Flow Matching e Dedicação}

Um outro modelo, para tratar o risco de descasamento entre ativos e passivos dos planos $\mathrm{BD}$ seria o cash flow matching. Esse modelo consiste na tentativa de se construir um portfolio cujo fluxo de caixa tenha adesão perfeita ao fluxo de caixa do passivo. No entanto, "o problema de se obter casamento exato entre fluxos de caixa é provavelmente inviável dados os instrumentos disponíveis no mercado [americano]" (Dahl, Meeraus e Zenios(1993)), ainda mais no mercado brasileiro, que é limitado em ativos. Assim, é necessário relaxar a restrição de cash flow matching, utilizando um modelo como o [DEDICATION], que consiste em minimizar o preço de um portfolio que imponha uma precedência dos fluxos de caixa dos ativos em relação aos do passivo. Em outras palavras, o modelo [DEDICATION] monta a carteira de menor preço (e, portanto, máxima rentabilidade) cujos fluxos de caixa antecedam os fluxos de caixa projetados para o passivo.

Seja a notação:

\section{$t$ indice apee roperseuta as datas eum vencimernos do passivoc At i periodo iransocerido entre as diasas de vencimento $t$ er $-\mathrm{l}$ : \\ $L_{\text {: }}$ pagamentodo passivoma data $\mathrm{r:}$ \\ G. : superivis na dina r. \\ $\rho$ : Lasa de reimestimenso.

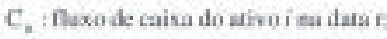 \\ $D_{\text {ir }}$ : valor do fluxode cavisa do ativo reimedido $z$ taxa perere as datas $f$ e $f-1$ $x$ : quartidade do ativo i presenca wa cartein.}

Para uma data $\tau$, o valor do fluxo de caixa reinvestido do ativo $i$ é obtido através da capitalização dos vencimentos ocorridos entre e aplicados à taxa $\rho$ :

$$
D_{i t}=\sum_{t=\mid t-1, t]} C_{i+1} \times(1+\rho)^{-t}
$$

O caixa gerado por cada componente do portfolio, adicionado ao superávit existente anteriormente corrigido pela taxa $\rho$, deverá ser igual à soma do vencimento do passivo na data com o novo superávit:

$$
\sum_{i} D_{i t} x_{i}+s_{t-1} \times(1+\rho)^{3 r}=L_{t}+s_{t}
$$

Um aspecto importante é que o risco de reinvestimento, ou seja, o risco do gestor não conseguir aplicar os fluxos de caixa intermediários à taxa $\rho$ pode ser mitigado ao se adotar um valor conservador para a mesma (por exemplo, zero). Dessa maneira, se a taxa de reinvestimento verificada vier a ser superior, a estratégia gerará gradualmente superávit.

Além disso, cabe ressaltar que é necessário impor não negatividade aos superávits $s$, de forma a garantir a precedência dos fluxos de caixa do ativo em relação aos do passivo, e, portanto, garantindo o dedication. O modelo fica, então:

Modelo [DEDICATION]:

$$
\begin{aligned}
& \min \sum_{i} P_{i} x_{i}+s_{0} \\
& \text { s.a.: } \\
& \sum_{i} D_{i \mathrm{r}} x_{i}+s_{z-1} \times(1+\rho)^{\Delta t}=L_{t}+s \\
& s_{\mathrm{r}} \geq 0, \forall \tau \\
& x_{i} \geq 0, \forall i
\end{aligned}
$$

onde $P_{i}$ é o preço do ativo ie $x_{i}$ é a quantidade do ativo $i$.

Uma limitação dos modelos apresentados reside na sua natureza determinística que não possibilita que se trabalhe com ativos cujo fluxo de caixa seja incerto, como, por exemplo, títulos de dívida de maior risco de crédito, papéis pós-fixados, papéis com variação cambial e ações. As alternativas são modelos estocásticos (Klaassen (1998)) que podem embutir as restrições de risco de cada papel, porém apresentam grande demanda computacional, em função do elevado número de variáveis e da forte necessidade de processamento, o que tornaria inviável sua implementação na instituição considerada. Na seqüência, portanto, buscar-se-á refinar os modelos apresentados para permitir a consideração dessas classes diferenciadas de ativos, sem, no entanto, recorrer a modelos de otimização estocástica. 


\section{O PROBLEMA DE INTERESSE}

Com a finalidade de aplicar os modelos anteriormente apresentados ao caso brasileiro, realizou-se um estudo em uma das mais importantes administradoras do país. A empresa iniciou suas atividades no Brasil no início da década de 90 e uma de suas principais atividades é a gestão de recursos de entidades de Previdência Complementar.

O estudo mencionado foi realizado tomando-se os dados reais da projeção atuarial do passivo de uma fundação cliente da administradora. O passivo foi projetado pela área atuarial da administradora, através da utilização de um aplicativo especializado, desenvolvido para uso interno. Os valores dos desembolsos líquidos a serem realizados pela patrocinadora para cobrir os benefícios ano a ano até 2032 foram fornecidos aos autores diretamente pela área atuarial. Em função disso, e devido à confidencialidade das informações, não é possível fornecer ao leitor estatísticas mais detalhadas a respeito da população.

A metodologia utilizada para projeção do passivo envolve a consideração das características etárias da população de participantes do plano e das tabelas de mortalidade aplicáveis a essa população. O aplicativo mencionado projeta os valores presentes dos benefícios concedidos e a conceder para cada período, com base na taxa de desconto de $6 \%$ a.a. A partir disso, calcula o superávit ou déficit do plano em cada ponto do tempo, definindo um valor de contribuição da patrocinadora necessário para sanear o plano em um determinado período. Vale destacar que o fluxo de caixa utilizado, indicado no Gráfico 1 , já considera as contribuições sugeridas para saneamento do plano.

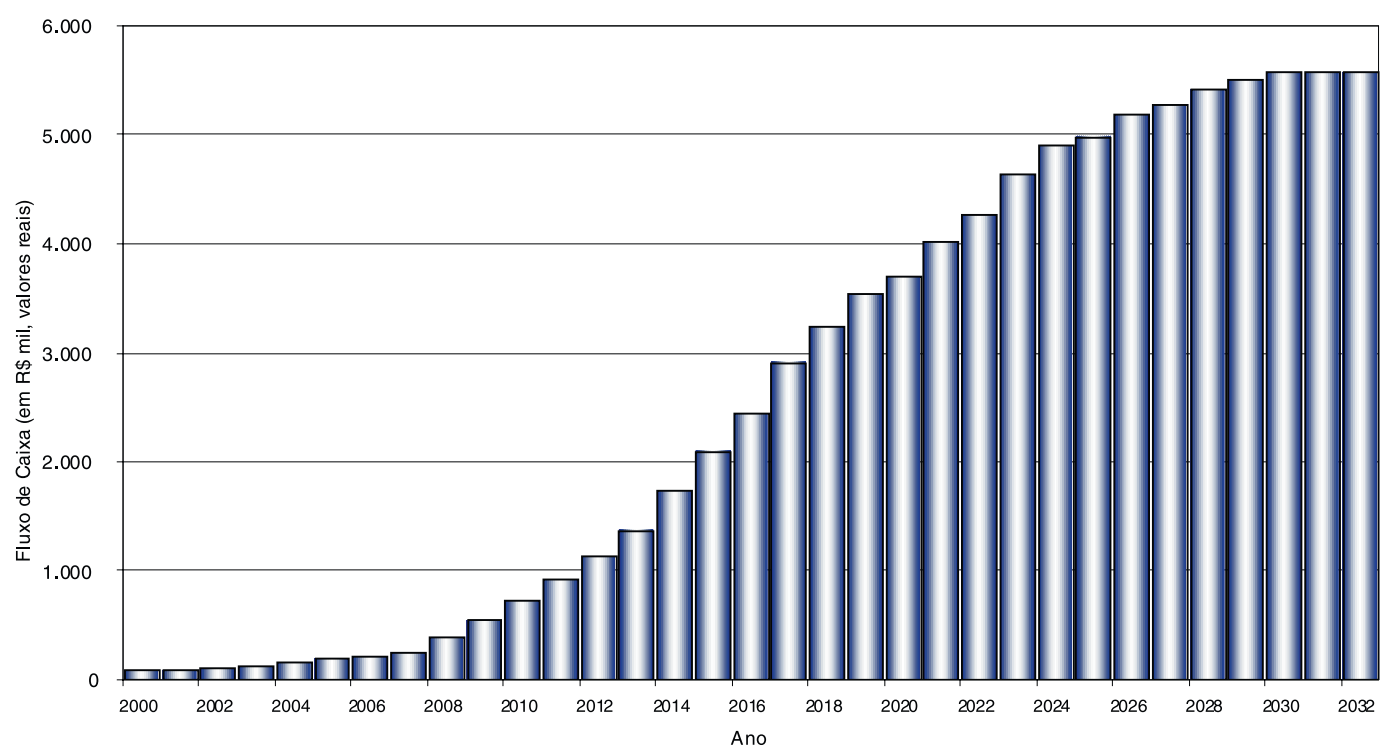

Gráfico 1: Projeção dos Fluxos de Caixa do Plano em Análise

Cabe ressaltar algumas premissas utilizadas no cálculo do passivo indicado anteriormente:

a) massa fechada de contribuintes, ou seja, o número de pessoas que entra e sai do plano está equilibrado;

b) taxa de juros de $10 \%$ a.a. para rentabilidade do ativo

c) taxa de desconto do passivo: $6 \%$ a.a.; d) inflação zero (ou seja, trata-se de um fluxo de caixa em moeda constante).

Com relação aos ativos utilizados na otimização, inicialmente levantou-se os fluxos de caixa de 237 ativos de emissão da República Federativa do Brasil, do Tesouro Nacional ou do Banco Central do Brasil existentes no mercado no dia 18/08/2000. Desses 237 ativos sendo 79 eram LFTs (ativos pós fixados),

\footnotetext{
${ }^{4}$ Embora tenha sido presumida essa taxa, ela não será uma premissa de nenhuma das otimizações a serem realizadas, pois seria uma fonte desnecessária de incertezas, e, uma
} vez estabelecida, já define a estratégia de saneamento do plano a ser implementada. 
47 LTNs (ativos pré fixados), 67 NBC-Es (papéis atrelados à variação cambial), 26 NTN-Ds (idem), 6 eram títulos da dívida externa brasileira renegociada (C-BOND, DCB, Discount, Exit, Par e El, denominados genericamente de Brady Bonds) e 9 eram Global Bonds (Global 01, Global 04, Global 07, Global 08, Global 09, Global 20, Global 27, Global 30, Global 40).

Com exceção dos Bradies e Globals, os preços dos ativos não puderam ser obtidos diretamente do mercado, pois não havia, na época, registros facilmente tratáveis de preços no Brasil. Assim, foi necessário presumir-se um preço calculado a partir dos fluxos de caixa trazidos a valor presente.

Para se calcular tais preços, bem como para se determinar as taxas internas de retorno, os dollar durations e dollar convexities dos ativos, foi necessário utilizar uma estimativa da curva de juros e da curva de cupom cambial ${ }^{5}$.

Os preços e curvas de juros utilizados para os ativos referem-se ao dia 18/08/2000. O fluxo de caixa considerado para o passivo refere-se aos benefícios pagos (como se eles fossem desembolsados no fim de cada ano) subtraídos das contribuições realizadas pela Patrocinadora e pelos participantes. As características do passivo, assim determinado, são: Dollar Duration $=\mathrm{k}_{\mathrm{L}}=-\mathrm{R} \$ 42.840 .429$ e Dollar Convexity $=Q_{L}=R \$ 741.258 .275$.

Os modelos utilizados para calcular a solução para o problema foram [IMMUNIZATION1], [IMMUNIZATION2] e [DEDICATION]. Serão feitas, no entanto, algumas alterações nas suas estruturas para que a análise seja mais robusta.

A alteração mais importante refere-se à imposição de uma restrição para o valor do portfolio. Como o patrimônio da Fundação deve ser aplicado integralmente, impôs-se que o valor da carteira fosse igual ao patrimônio da Fundação. Para garantir a consistência do modelo, desse patrimônio foi subtraído o valor presente da reserva restante no último ano do período estudado, pois ela não foi considerada para o cálculo dos fluxos de caixa nem para a determinação do dollar duration e dollar convexity do passivo. Esse valor presente, no entanto, é necessário para cobrir os desembolsos após 2032.

Para o caso do modelo [DEDICATION], no qual a função objetivo é o próprio preço da carteira, a introdução dessa restrição implica a mudança da variável a ser minimizada. A nova função objetivo definida foi a soma dos superávits ao longo do tempo. Como se sabe que os superávits são positivos, por imposição das restrições do modelo, quando se minimiza a soma dos mesmos, está-se impondo que haja a máxima coincidência possível entre os fluxos de caixa de ativos e passivos, que é o objetivo do modelo [DEDICATION]. O novo modelo, [DEDICATION1], pode ser reescrito como:

Modelo [DEDICATION1]:

$$
\begin{aligned}
& \min \sum_{t} s_{t} \\
& \text { s.a.: } \\
& \sum_{i} D_{i t} x_{i}+s_{\tau-1} \times(1+\rho)^{\mathrm{a} \tau}=L_{\tau}+s_{\tau}, \forall \tau \\
& D_{i t}=\sum_{i=\{r-1, t\}} C_{i t} \times(1+\rho)^{t-t}, \forall \tau \\
& \sum P_{i} \times x_{i}=P L \\
& s_{r} \geq 0, \forall \tau \\
& x_{i} \geq 0, \forall i
\end{aligned}
$$

\footnotetext{
${ }^{5}$ As curvas foram obtidas através da interpolação linear das taxas de juros futuras dos vértices de maior liquidez negociados na BM\&F.
} 


\section{RESULTADOS}

Os modelos [IMMUNIZATION1] e [IMMUNIZATION2] foram resolvidos através da utilização da ferramenta Solver do Excel, e o modeIo [DEDICATION] foi resolvido com a utilização do software GAMS, General Algebraic Modeling System, um aplicativo profissional voltado para a resolução de problemas de otimização desenvolvido pela GAMS Development Corporation. Este último modelo é composto por 38 equações, 272 variáveis e 1137 parâmetros não nulos.

A resposta do modelo [IMMUNIZATION1] indicou aplicação de $96 \%$ do patrimônio na NTN-D de taxa interna de retorno igual a 20,2\%a.a. (máxima), e os demais $4 \%$ no $C-B O N D$, que é um ativo de mais longo prazo, apresentando vencimento apenas em 2014. Em outras palavras, o modelo investe o máximo possível do capital no ativo de maior rentabilidade, porém de reduzido dollar duration, compensando a diferença de duration entre esse ativo e o passivo através de uma alocação no ativo de longo prazo, o C-BOND.

Para o modelo [IMMUNIZATION2], a solução indicou aplicação de $82 \%$ do capital em LFTs, $1 \%$ no $C$ BOND e $17 \%$ no Global 40.

Para o modelo [DEDICATION], utilizando-se a taxa de reinvestimento de $3 \%$ a.a., ou seja, assumindo que as taxas pós-fixadas garantem rentabilidade $3 \%$ a.a. superior aos aumentos de salários, a resposta do modelo indicou a aplicação de $64 \%$ num ativo de curto prazo (NTN-D de vencimento em 01/09/2000) e os demais $36 \%$ no GLOBAL 30, outro ativo de elevado dollar duration, pois possui vencimento em 2030.

Os resultados que foram obtidos são exatamente os esperados segundo a literatura, ou seja, no caso do [IMMUNIZATION1], a resposta é uma carteira composta pelo ativo de maior taxa interna de retorno juntamente com um ativo de alto dollar duration, para balancear o duration da carteira. A resposta do [IMMUNIZATION2], por outro lado, dispersa o fluxo de caixa da carteira investindo uma parcela significativa de recursos (18\%) em Bradies, e o restante em títulos pós-fixados. Cabe destacar, no entanto, que, para se desenvolver uma análise do tipo [IMMUNIZATION], é necessário se ter uma estimativa das taxas de juros futuras, o que consiste, por si só, em tarefa razoavelmente complexa, e que tem forte influência sobre o resultado. Além disso, há uma cultura entre os atuários de se utilizar a taxa arbitrária de $6 \%$ a.a. (de ganho real) para descontar o passivo a valor presente, decorrente do fato de que esta é a taxa máxima fixada em lei para se calcular o superávit/déficit corrente da Fundação. Se os parâmetros do passivo (duration e convexity) fossem calculados com base nessa taxa arbitrária, as soluções também seriam completamente diferentes.

A resposta dos modelos [IMMUNIZATION] pode também receber uma outra interpretação. É sabido que, para certos planos de aposentadoria complementar, há restrições para se investir nos títulos de dívida brasileiros emitidos no exterior. Portanto, os portfolios sugeridos pelos modelos em análise apresentarão outros custos de implementação, se de fato fossem implementados.

No entanto, pode-se dar uma outra interpretação para a solução apresentada, se for analisada a correlação entre os retornos do C-BOND, do Discount (bradies que fazem parte da solução do modelo [IMMUNIZATION]) e do IBOVESPA. O gráfico, a seguir, mostra os retornos acumulados do IBOVESPA, C-BOND e Discount deflacionados pelo IGP-M desde janeiro de 1995.

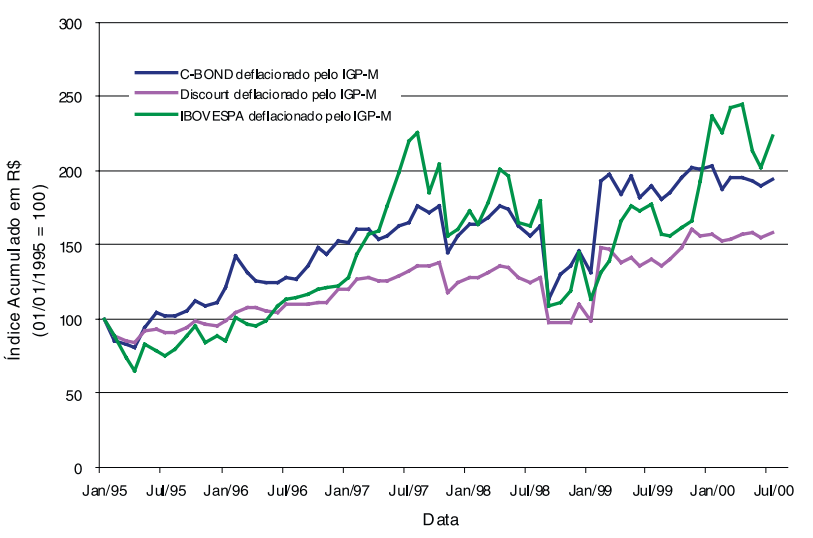

Fonte: Economática e Bloomberg

\section{Gráfico 2: Retornos Acumulados do IBOVESPA, C-Bond e Discount, Deflacionados pelo IGP-M}

O coeficiente de correlação dá uma boa idéia da variação conjunta de preços entre o IBOVESPA e os Bradies. Se for calculado esse coeficiente para as séries de retornos mensais do $C$-BOND e do IBOVESPA deflacionadas pelo IGP-M, obtem-se o valor de 0,63. Para o IBOVESPA comparado com o Discount, tem-se o valor de 0,56. Esses valores são relativamente altos, confirmando a possível 
existência de uma forte relação entre os retornos dos Bradies e do IBOVESPA.

Portanto, uma forma alternativa de se implementar a solução do modelo seria montar uma carteira cuja distribuição dos ativos fosse dada em função da resposta do modelo, ou seja, investir $82 \%$ da carteira nos ativos de renda fixa indicados (LFTs) e os demais $18 \%$ em ativos de renda variável, por exemplo, em um fundo de ações que busque replicar a performance do IBOVESPA.

Vale lembrar, no entanto, que, como os fluxos de caixa do IBOVESPA são mais incertos, o risco do novo portfolio construído é maior do que o risco da solução inicial do problema. Logo, para que se fosse mais preciso, poder-se-ia ajustar a exposição em IBOVESPA da carteira em função das volatilidades dos retornos do IBOVESPA e dos Bradies. A volatilidade nada mais é do que o desvio-padrão dos retornos de cada ativo. A volatilidade mensal do IBOVESPA, para o período considerado, foi de $11,7 \%$ a.m., enquanto a volatilidade do $C$ - $B O N D$ foi de $9,4 \%$ a.m. Como a volatilidade dos retornos dos ativos pósfixados (LFT) é muito baixa comparada à do IBOVESPA, pode-se concluir que uma carteira composta por $20 \%$ em LFTs e $80 \%$ em IBOVESPA possui volatilidade igual à do $C-B O N D$ (pois $)^{6}$. Portanto, dos $18 \%$ em $C$-BOND que se tinha na resposta inicial, ter-se-ia que investir 20\% em LFTs (que representam $20 \%$ x $18 \%=3,6 \%$ da carteira total) e $80 \%$ em bolsa (que representam $80 \%$ x $18 \%=14,4 \%$ da carteira). Assim, para a carteira modificada, o total seria de $14,4 \%$ aplicado em IBOVESPA e $85,6 \%$ em LTFs, de forma que se mantivesse a volatilidade global constante.

Essa resposta apresenta aplicação prática imediata, pois admite implicitamente que se pode construir uma carteira com características de duration e convexidade adequadas às características do passivo aplicando em ativos de renda fixa e renda variável adaptadas ao passivo do plano e não a uma meta atuarial arbitrariamente fixada.

Em seguida será feita a análise da resposta do modelo [DEDICATION]. Para esse modelo, utilizando-se a taxa de reinvestimento de $3 \%$ a.a., tem-se uma resposta semelhante à do modelo
[IMMUNIZATION2], com uma parcela da carteira sendo investida em um ativo de elevado prazo de vencimento ( $G L O B A L 30$ ), e a maior parte ficando investida em ativos de curto prazo (vencimento em 01/09/2000), de maior rentabilidade.

Porém, especialmente no caso do modelo [DEDICATION], a resposta obtida varia conforme as taxas de reinvestimento assumidas, ou seja, seria mais adequado que se estudasse o problema variando-se essa taxa, realizando-se uma análise de sensibilidade em relação a esse fator.

Para isso, calculam-se os resultados utilizando taxas de reinvestimento variando de $12 \%$ a.a. a $10 \%$ a.a., de $1 \%$ em $1 \%$. A taxa de $-10 \%$ a.a. é a mínima taxa que ainda permite a existência de soluções viáveis. As soluções estão resumidas na Tabela a seguir.

\section{Tabela 1: Análise de Sensibilidade do Modelo [DEDICATION] em Relação à Taxa de Reinvestimento}

\begin{tabular}{|c|c|c|c|c|c|}
\hline $\begin{array}{l}\text { Taxa de } \\
\text { Reinves- } \\
\text { timento }\end{array}$ & $\begin{array}{c}\text { NTN-D } \\
(01 / 09 / 2000) \\
(\%)\end{array}$ & $\begin{array}{c}\text { NTN-D } \\
(01 / 01 / 2001) \\
(\%)\end{array}$ & $\begin{array}{c}\text { Discount } \\
\text { (\%) }\end{array}$ & $\begin{array}{c}\text { GLOBAL } 27 \\
(\%)\end{array}$ & $\begin{array}{c}\text { GLOBAL } 30 \\
(\%)\end{array}$ \\
\hline $10 \%$ & 100 & 0 & 0 & 0 & 0 \\
\hline $9 \%$ & 100 & 0 & 0 & 0 & 0 \\
\hline $8 \%$ & 100 & 0 & 0 & 0 & 0 \\
\hline $7 \%$ & 0 & 97 & 3 & 0 & 0 \\
\hline $6 \%$ & 0 & 89 & 0 & 0 & 11 \\
\hline $5 \%$ & 0 & 80 & 0 & 0 & 20 \\
\hline $4 \%$ & 72 & 0 & 0 & 0 & 28 \\
\hline $3 \%$ & 64 & 0 & 0 & 0 & 36 \\
\hline $2 \%$ & 57 & 0 & 0 & 0 & 43 \\
\hline $1 \%$ & 51 & 0 & 0 & 0 & 49 \\
\hline $0 \%$ & 0 & 45 & 0 & 0 & 54 \\
\hline$-1 \%$ & 0 & 40 & 0 & 5 & 55 \\
\hline$-2 \%$ & 0 & 34 & 0 & 10 & 56 \\
\hline$-3 \%$ & 0 & 29 & 0 & 14 & 57 \\
\hline$-4 \%$ & 0 & 24 & 0 & 17 & 58 \\
\hline$-5 \%$ & 0 & 20 & 0 & 21 & 59 \\
\hline$-6 \%$ & 0 & 16 & 0 & 23 & 60 \\
\hline$-7 \%$ & 0 & 12 & 0 & 26 & 62 \\
\hline$-8 \%$ & 0 & 9 & 0 & 28 & 63 \\
\hline$-9 \%$ & 0 & 6 & 0 & 30 & 64 \\
\hline$-10 \%$ & 0 & 3 & 0 & 32 & 66 \\
\hline
\end{tabular}

Como se pode perceber, quando as taxas de reinvestimento esperadas são altas, o modelo tende a aplicar os recursos em ativos com vencimento no curto

\footnotetext{
${ }^{6}$ Como a volatilidade das LFTs está sendo desprezada, desconsiderou-se o termo correspondente às covariâncias, pois a covariância de uma constante com uma variáve aleatória qualquer é nula. Dessa forma, a expressão de cálculo do risco torna-se linear
} 
prazo, para se aproveitar dos rendimentos do mercado de juros. No entanto, quando essas taxas vão sendo reduzidas, ou seja, conforme o modelo se torna conservador em relação às taxas de reinvestimento, os fluxos de caixa tendem a se dispersar e o modelo passa a investir nos títulos de longo prazo, no caso, Discount, Global 27e Global 30. O Gráfico 3 mostra a exposição da carteira em ativos de longo prazo (Bradies e Globals) em função da taxa de juros real esperada no longo prazo.

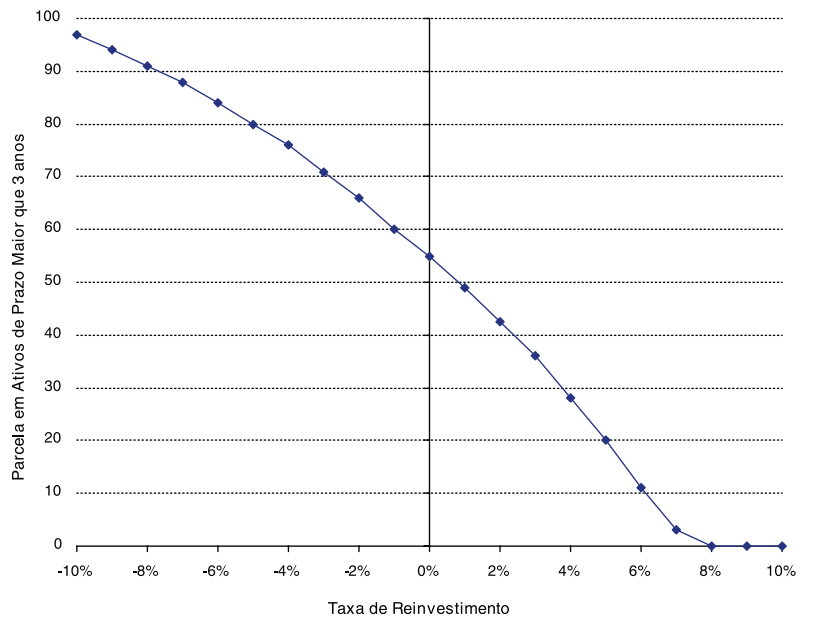

\section{Gráfico 3: Participação de Ativos de Longo Prazo na Solução do Modelo [DEDICATION] em Função da Taxa de Reinvestimento}

Cabe destacar que as taxas negativas utilizadas corresponderiam a situações em que os juros pós-fixados rendessem menos que a variação dos pagamentos de benefícios. Quando essas taxas são muito negativas, o problema acaba se tornando inviável, como ocorre quando a taxa de reinvestimento é suposta inferior a $-10 \%$.

Deve-se lembrar, no entanto, que a taxa de reinvestimento deve ser tomada como a taxa a que se poderão investir os ativos descontada da taxa de variação esperada para o passivo, que é a variação salarial. A variação salarial é composta por uma expectativa de inflação adicionada de uma projeção de variação real. Portanto, a taxa de reinvestimento é equivalente à taxa de juros reais esperada subtraída da expectativa de variação real de salários. Dessa forma, se forem projetadas taxas de juros reais de $7 \%$ a.a. e crescimento de salários real por volta de 3\% a.a., ter-se-ia uma taxa de reinvestimento de aproximadamente 4\% a.a., e, portanto, uma alocação sugerida em ativos de longo prazo de cerca de $30 \%$.

Um outro refinamento para o modelo [DEDICATION] foi feito dividindo-se os fluxos de caixa projetados para o passivo numa base mensal, a partir dos dados calculados anualmente. A primeira parte em que se dividiu o problema inclui os vencimentos do passivo até 2004, em base mensal. A segunda parte corresponde aos vencimentos entre 2005 e 2009, também em base mensal, e a terceira parte engloba os vencimentos de 2010 em diante, porém em base trimestral até 2008 e em base anual daí em diante. Os subproblemas estão indicados na Tabela 2 , a seguir. A taxa de reinvestimento utilizada foi zero.

Tabela 2: Subdivisão do Modelo [DEDICATION]

\begin{tabular}{l|l|l|l|c}
\hline Período & Base & Função Objetivo & Restrições & Número de Variáveis \\
Até 2004 & Mensal & Mínimo preço & Superávits positivos & 291 \\
\hline De 2002 até 2009 & Mensal & Mínimo preço & Superávits positivos & 298 \\
\hline De 2010 até 2032 & $\begin{array}{l}\text { Trimestral até 2028, } \\
\text { inclusive }\end{array}$ & $\begin{array}{l}\text { Mínimos superávits } \\
\text { intermediários }\end{array}$ & Superávits positivos & 299 \\
& Anual daí em diante & $\begin{array}{l}\text { Preço igual à diferença } \\
\text { entre o patrimônio } \\
\text { disponível e os preços } \\
\end{array}$ & dos subproblemas 1 e 2. \\
\hline
\end{tabular}

As soluções de cada um dos subproblemas estão listadas na Tabela 3.

Tabela 3: Soluções dos Três Subproblemas do Modelo [DEDICATION]

\begin{tabular}{l|l|ll}
\hline Período & Composição & Valor da Carteira \\
Até 2004 & $92,5 \%$ em LFTs de 20 vencimentos diferentes - 1,8\% em LTNs - 5,6\% no GLOBAL 01 & R $\$ 375.618$ & R $\$ 751.656$ \\
\hline Até 2009 & $15 \%$ em C-BOND - 69\% em GLOBAL 08 - 16\% em GLOBAL 09 & R 25.704 .161 \\
\hline Até 2032 & $38 \%$ NTN-D (vencimento set/00) - 58\% GLOBAL 30 - 4\% GLOBAL 27 & \\
\hline
\end{tabular}


A solução acima é bastante semelhante à que se obteve anteriormente, mas traz mais uma informação interessante: para se cobrirem os fluxos de passivo no curto prazo, basta uma parcela de $1,4 \%$ do patrimônio total do plano (que é o valor da função objetivo, de $R \$ 375.618$ ), deixando o restante livre para se cobrirem os fluxos de longo prazo.

Vale destacar, porém, que, ao ser dividido o problema em três partes, a soma das soluções individuais não será a solução do problema global. Porém, a divisão em três problemas de menos de 300 variáveis, possíveis de se resolverem na versão empregada do software GAMS, pôde dar uma indicação de como seria a resposta do modelo global.

Evidentemente, os resultados apresentados são interessantes como aplicação dos modelos de Asset/ Liability Management no Brasil. No entanto, eles apresentam algumas limitações que podem ser trabalhadas e podem gerar sofisticações dos modelos.

Uma das limitações é o fato de que todos os modelos descritos não consideram a incerteza de ativos e passivos. No caso do passivo, existe incerteza nos fluxos de caixa porque é necessário, na sua estimativa, considerar-se uma série de variáveis aleatórias, como por exemplo, idades de aposentadoria dos participantes, vida restante, salário no momento da aposentadoria etc. A maioria desses riscos não pode ser compensada com a montagem da carteira; no entanto, pelo menos um deles pode ser levado em consideração pelos administradores, que é a sua atualização com base na inflação.

Isso pode ser feito se for acrescentado à função objetivo do modelo [DEDICATION] uma penalidade em função do risco de cada ativo. O risco dos fluxos de caixa dos ativos existe porque eles não necessariamente serão corrigidos pelos índices de inflação. Sendo assim, é preciso considerar o descolamento provável entre esses fluxos de caixa e os fluxos de caixa do passivo causados pela correção dos benefícios pagos com base no IGP-M. Além disso, muitos dos ativos utilizados têm o fluxo de caixa atrelado também à variação cambial, o que representa um risco adicional.

Uma forma de se incluir esses fatores na otimização é analisar, com base em dados históricos, as diferenças entre, por exemplo, a variação cambial e a variação do IGP-M. Isso pode ser feito considerando-se o desvio-padrão das diferenças entre a variação do dólar e do IGP-M. Mais especificamente, para cada classe de ativo, dever-se-ia desenvolver a análise histórica de retornos relativos ao IGP-M, conforme esquematizado na Tabela 4 , a seguir:

\section{Tabela 4: Riscos Associados a Cada uma das} Classes de Ativos

\begin{tabular}{l|l}
\multicolumn{1}{c|}{ Ativo } & Risco \\
Pré fixado (LTN) & 0 - IGP \\
\hline Pós fixado (LFT) & Selic $^{7}$ - IGP \\
\hline Cambial (NTN-D/NBC-E) & US\$ - IGP \\
\hline Atrelado ao IGP-M (NTN-C) & 0 \\
\hline Brady Bonds (C-BOND, IDU) & US\$ - IGP \\
\hline
\end{tabular}

É possível notar que esse tipo de abordagem permite dar um tratamento muito mais adequado aos títulos pós-fixados, cujos fluxos de caixa seriam diferenciados dos fluxos dos ativos pré-fixados pela incerteza, se fosse aplicado um modelo [DEDICATION] modificado.

Conforme mencionado, há também outra abordagem para tratamento do risco dos ativos, que é a otimização estocástica, que não se analisará em função da limitação computacional.

\section{CONSIDERAÇÕES FINAIS}

Foi realizada uma aplicação pioneira dos modelos de imunização e dedicação ao caso de um fundo de pensão brasileiro. As respostas obtidas podem ser consideradas bastante satisfatórias. Em especial, a análise de sensibilidade do modelo de dedicação em relação à taxa de juros real esperada traz bastante informação ao gestor dos ativos para escolher a carteira a ser implementada.

Cabe destacar, também, a importância do trabaIho para a administradora na qual ele foi desenvolvido. Desde a publicação da Resolução 2720 (e 2829) do CMN, tem havido um crescente interesse dos clientes pela utilização de modelos de Asset/Liability Management na determinação das alocações de suas carteiras em Renda Fixa e Renda Variável. Nesse contexto, há uma tendência de os administradores de recursos perderem o mandato da gestão da alocação de ativos para empresas especializadas, ficando restritos à administração dos segmentos e, portanto,

A taxa Selic é a taxa de jurios aplicada aos títulos públicos federais pós fixados. 
passando a oferecer um produto de menor valor agregado. Dessa forma, esses modelos apresentam uma vantagem importante, pois são de uma sofisticação muito

maior que os produtos hoje oferecidos no mercado, que, muitas vezes, não consideram diretamente a necessidade de se atender aos fluxos de caixa do passivo.

\section{REFERÊNCIAS BIBLIOGRÁFICAS}

BLAKE, D.; CARNS, A.J.G.; DOWD, K. Pensionmetrics: stochastic pension plandesign and value-at-risk during accumulation phase. Insurance: Mathematics and Economics, v.29, p.187-215, 2001.

BERNSTEIN, R. Style investing: unique insight into equity management. New York : John Wiley \& Sons, 1995.

CREMER, H., ;PESTIEAU, P. Reforming our pension system: Is it a demographic, financial or political problem?. European Economic Review, v.44, p.974-983, 2000.

DAHL, H.; MEERAUS, A.; ZENIOS, S. A. Some financial optimization models: I Risk management. IN: ZENIOS, Stavros A. (org.). Financial optimization. Cambridge : Cambridge University, 1993.

Some financial optimization models: II Financial engineering. IN: ZENIOS, Stavros A. (org.). Financial optimization. Cambridge : Cambridge University, 1993.

DAVIDSON, S.; STICKNEY, C. P., WEIL, R. L. Financial accounting: an introduction to concepts, methods, and uses. $5^{\mathrm{a}}$ ed. New York : The Dryden, 1988.

DEMBO, R. Scenario optimization. Annals of Operations Research, v. 30, 1991.

Scenario immunization. IN: ZENIOS, Stavros A. (org.). Financial optimization. Cambridge : Cambridge University, 1993.
DIMSON, E., MUSSAVIAN, M. Three centuries of asset pricing. Journal of Banking and Finance, 23 (1999) 1745-1769.

FABOZZI, F. J. Fixed Income Readings for the Chartered Financial Analyst $\Theta$ Program. New Hope : Frank J. Fabozzi Associates, 2000.

GRINOLD, R. C., KAHN, R. N. Active portfolio management. New York : McGraw-Hill, 1995.

HAUGEN, R. A. Modern investment theory. $2^{\mathrm{B}}$ ed. New Jersey : Prentice Hall, 1989.

KLAASSEN, P.. Financial asset pricing theory and stochastic program models for asset/liability management: a synthesis. Management Science, v. 44, n. 1, Janeiro de 1998, p. 31-48.

LEIPPOLD, M., TROJANI F., VANINI P. A geometric approach to multiperiod mean variance optimization of assets and liabilities. Journal of Economic Dynamics \& Control, In Press, 2003.

MARKOWITZ, Harry M. Portfolio selection. Journal of Finance, v. 7, n. 11952.

Mean-variance analysis in portfolio choice and capital markets. Oxkord, UK : Blackwell, 1987.

SALNIK, B. International investments. $3^{\mathrm{a}}$ ed. Addison, 1996.

TENDÊNCIAS. Previdência privada no Brasil: Princípios gerais, perspectivas e riscos. 1999.

\section{NOTA:}

Endereço do autor:

NICOLAS SAAD

Av. Brig. Faria Lima, 3064

São Paulo - SP

1451-000

CELMA O. RIBEIRO

Av. Almeida Prado, trav.2, 128 - Cidade Universitária - Butantã

São Paulo - SP

05508-900 